УДК 902.2 (470.325)

https://doi.org/10.24852/2587-6112.2020.5.174.181

\title{
ОБ ИСТОРИИ ИЗУЧЕНИЯ КУРГАННЫХ ДРЕВНОСТЕЙ, РАСПОЛОЖЕННЫХ НА ТЕРРИТОРИИ СОВРЕМЕННОЙ БЕЛГОРОДСКОЙ ОБЛАСТИ
}

\section{(C) 2020 г. Я.С. Святой, А.А. Костылёва}

Авторами статьи представлены результаты изучения истории изучения курганов. Территория современной Белгородской области до 1954 г. входила в состав Воронежской и Курской губерний / областей. В этот период изучение древностей происходит в русле развития археологии указанных регионов. С конца 1950-ых гг. в области работают крупные академические археологические экспедиции, начинает формироваться актуальный банк данных о курганных памятниках региона. В 2000-х гг. проводится сплошное обследование области на предмет наличия курганов силами местных экспедиций.

Ключевые слова: археология, курган, Белгородская область, Курская, Воронежская губернии, история археологии, академические экспедиции, краеведение.

\section{THE HISTORY OF THE STUDY OF BARROW ANTIQUITIES LOCATED IN THE TERRITORY OF MODERN BELGOROD REGION}

\section{Ya.S. Svyatoy, A.A. Kostileva}

The history of investigation the barrows are represented by the authors. Until 1954, the territory of contemporary Belgorod region was part of the Voronezh and Kursk governorates / regions. During this period, the study of antiquities took place in line with the development of archaeology in these regions. Since the late 1950s, large academic archaeological expeditions have been conducted in the region, and a current databank of barrow monuments of the region is starting to be formed. In the 2000 s, a complete survey of the region was carried out by local expeditions in order to reveal the presence of barrows.

Keywords: archaeology, mound, Belgorod region, Kursk, Voronezh province, history of archaeology, academic expeditions, local history.

Первые археологические изыскания курганных древностей на территории современной Белгородской области приходятся на середину XIX - начало XX вв. В этот период регион своей западной и центральной частью входил в состав Курской губернии, восточной - Воронежской губернии. В целом с точки зрения археологической привлекательности указанная территория не считалась перспективной для проведения изысканий. Однако, несмотря на это, сведения о наличии курганов и майданов на данной территории мы встречаем уже с середины XIX в.

В 1873 г. по представлению Д.Я. Самоквасова Центральным статистическим комитетом через губернские статистические комитеты разослана в волостные правления анкета «О курганах и городищах», которая состояла из 12 вопросов (Спицын, 1903, с. 1). В рамках этого запроса собраны первые наиболее обширные сведения о распространении курганных древностей на территории современной Белгородской области. В частности, сведения о курганах с территории муниципальных образований, ранее входивших в состав Валуйского, Бирюченского, Остро- гожского уездов Воронежской губернии, в 1887 г. опубликованы в виде отдельного приложения, сопровожденного картой в Материалах для истории Воронежской и соседних губерний (Материалы..., 1887, с. 414-416, 419). Также указанные данные напечатаны Спицыным А.А. в 1896 г. в записках Императорского Русского археологического общества (Спицын, 1896, с. 138).

Сведения, собранные по Белгородскому, Грайворонскому, Корочанскому, Новооскольскому, Старооскольскому уездам Курской губернии, в 1874 году опубликованы в Трудах Курского статистического комитета (Спицын, 1903, с. 3). В 1901 г. А.А. Спицын отмечает, что наибольшее количество курганов в Курской губернии сосредоточено по Сейму, Пслу, Ворскле, Северскому Донцу и Осколу (Спицын, 1901, с. 98).

Интересно отметить, что анкета Д.Я. Самоквасова впервые апробирована именно на примере Курской и Черниговской губерний еще в 1872 г. Так, в сентябре указанного года на страницах Курских епархиальных ведомостей размещено отношение Д. Самоквасова на имя епископа Курского Сергия, в котором 
он указывает на необходимость составления географической карты городищ и курганов и просит предложить приходским священникам, «как лицам, наиболее образованным на местности», ответить на простые вопросы в отношении указанных древностей. На что епископ Сергий не только дал резолюцию о сборе описаний древностей, но и указал на необходимость представления редакцией собранных сведений лично ему, а также поручил к публикации наиболее «занимательные статьи» (Отношение..., 1872, с. 1028). Уже в 1873 г. на страницах Ведомостей находим описание памятников, в том числе курганов, вблизи села Староселье Грайворонского уезда (в настоящее время территория Краснояружского района), составленное священником Александром Софроновым (Софронов, 1873, с. 128).

Следующим крупным изданием, на страницах которого описаны курганные памятники, расположенные в западной и центральной части региона (Белгородского, Грайворонского, Корочанского и Новооскольского уездов), входивших в состав Курской губернии, становится «Памятники старины и нового времени и другие достопримечательности Курской губернии» краеведа Н.И. Златоверховникова (Златоверховников, 1902, с. 44, 50-52, 56-57, $61,92)$. В нем также он сообщает, что большой курган диаметром в 12 сажень, находящийся в 5 верстах от слободы Стрелецкой раскопан местным священником Иваном Никитиным. Два года спустя на общем собрании Курской губернской архивной комиссии А.Н. Кобылиным зачитано сообщение «Зеленый курган» (ныне Прохоровский район), в котором он не только приводит подробное описание данного памятника, но и упоминает о летописно известном «Думном кургане» (Кобылин, 1904, с. 25). В 1910 г. на собрании указанной комиссии К.П. Сосновским представлен очередной доклад об изучении курганных древностей Обоянского уезда. Исследователем приводится описание курганов, расположенных в границах современных Прохоровского, Ивнянского, Ракитянского районов (Сосновский, 1911, с. 299).

Исследования курганных древностей восточной части области, входивших в Воронежскую губернию, в 1905 г. проводит членсотрудник Археологического института Н.Е. Макаренко. Проводя изыскания в окрестностях с. Герасимовка (ныне Валуйский район), он отмечает, что окружающая слободу мест- ность «наполнена насыпями в изобилии; как возвышенности, так и сравнительно низкие места покрыты курганами и майданами всевозможных форм и величин» (Макаренко, 1906 , с. 145). В том же году им раскопано 3 кургана в районе Герасимовки, а также осмотрен разграбленный курган вблизи Староивановки (ныне Волоконовского района) (Макаренко, 1906, с.145-149, 154-155).

В 1909 г. еще один курган на выгоне города Валуйки раскопан профессором СанктПетербургского университета С.Ф. Платоновым (Сведения..., 1910, с. 84). Подробно этот эпизод описан в статьях Е.Ю. Захаровой и В.В. Митрофанова (Захарова, 2014, с. 136-140; Митрофанов, 2015, с. 113-121).

В связи с военными и революционными событиями и без того малочисленные исследования курганных древностей в регионе практически сходят на нет. Силами местных краеведческих музеев в этот период в основном обследуются лишь поселения. Исключение составляют работы 1932 г. харьковского археолога И.Н. Луцкевича, которым раскопаны курганы катакомбной культуры у с. Уразово и с. Герасимовка Валуйского района. Полученные материалы хранились в Харьковском музее, но погибли в годы ВОВ, сохранились лишь зарисовки сосудов, сделанные Т.В. Поповой еще до войны (Попова, 1955, с. 82). Еще одна экспедиция снаряжена в Старооскольский район в 1934 г. ГАИМК с целью выявления, учета и изучения археологических памятников в зоне работ по сооружению ж/д ветки на участке от г. Старый Оскол до с. Коробково. В ходе разведки указанной местности зафиксировано 8 курганных групп, один курган раскопан (т. н. Пьянов курган), также произведена зачистка на месте ранее разрушенного кургана (Археологические исследования..., 1941, с. 164).

В послевоенное время первые и, как показала история, одни из наиболее значимых по результатам работы по исследованию курганов в регионе проводит Донская (Скифская лесостепная) экспедицией ИИМК (ИА) АН СССР. В этот период возглавлявший экспедицию П.Д. Либеров в связи со своими научными интересами активно проводит в Подонье раскопки и разведки скифских памятников (Захарова, 2008, с. 63). В 1960, 1961, 1964 гг. экспедицией под его руководством выявлено 4 курганных могильника в районе г. Алексеевка Алексеевского района, по два в Красногвардейском и в Красненском районах (Архео- 
логические памятники..., 1993, с. 2, 3, 15, 16, 23).

В 1961 г. разведками Воронежской лесостепной экспедиции обследован курганный могильник в с. Дуровка Красненского района, a c 1964 г. начаты его планомерные раскопки. Бессменным руководителем археологических изысканий Дуровского могильника являлась А.И. Пузикова (в 1964-1965 гг. раскопано 10 насыпей, в 1985-1987 гг. - 13). По итогам раскопок получен богатый и разнообразный вещевой комплекс, соотносимый с т. н. среднедонским локальным вариантом лесостепной скифской культуры. Памятник хорошо опубликован и в известной степени является эталонным для указанной территории (Пузикова, 2017, с. 6).

В 1968 г. исследования разрушенного кургана в районе города Валуйки проводит А.Д. Пряхин. В результате изучены погребения катакомбной культуры (Пряхин, 1968). Четырьмя годами позже (в 1972 г.) в Валуйском районе (с. Шелаево) под руководством преподавателя местного педагогического училища М.И. Карагодина археологические исследования производятся на сильно разрушенном экскаватором кургане «Кубаева могила», где по итогам обнаружено погребение катакомбной культуры, снабженное богатым для этого времени погребальным инвентарём (Карагодин, 1977, с. 230). В 1977 г. отрядом Советско-Венгерской экспедиции Института археологии АН СССР под руководством Г.Е. Афанасьева выявлено 12 курганных памятников в Алексеевском и Красногвардейском районах (Археологические памятники..., 1993, с. 2, 15).

В 1970-х гг. с целью подготовки Свода памятников истории и культуры народов России разведочные работы в Белгородской области ведет Центрально-Черноземный отряд Института археологии АН СССР под руководством А.В. Кашкина. По результатам 10-летних исследований он приводит следующую, как нам кажется, показательную фразу: «Юг Курской и север Белгородской областей представляют собой как бы огромный курганный могильник. Здесь выявлено около 200 одиночных курганов и небольших курганных могильников, протянувшихся в направлении запад-восток от р. Снагость до р. Оскол. Наибольшей концентрации курганы достигают в верховьях Псла, Сейма и Северского Донца» (Кашкин, 1993, с. 70). Тем самым автор повторяет вывод Спицына А.А. 1901 г. о характере распространения курганных памятников в регионе.

С 1970 г. активную деятельность по изучению археологических памятников Поосколья начинает учитель школы п. Волоконовка Волоконовского района А.Г. Николаенко. В 1973, 1974, 1979 гг. краеведческой группой «Алан» под его руководством выявлено 50 курганных памятников в Волоконовском районе, 1 - в Валуйском районе, 1 в 1980 г. - в Новооскольском районе (Археологические памятники..., 1992 , с. 8-13; 1995, с. 12, 18). Два курганных памятника в 1970-х гг. в бассейне р. Ворскла (в Борисовском и Яковлевском районах) выявлены учителем школы п. Борисовка Борисовского района А.Ф. Евминовой (Археологические памятники..., 1992, с. 10, 43). В 1989 г. при переобследовании памятников, выявленых А.Ф. Евминовой в верховьях р. Ворскла в пределах Грайворонского района, С.И. Воловик выявляет еще один курганный могильник - 1 (Археологические памятники..., 1992, c. 48$)$.

В 1980 г. среди прочих поселенческих памятников в Алексеевском районе одна курганная группа обнаружена воронежским археологом В.В. Килейниковым. Кроме того, им зафиксирован разрушенный курган на территории молочно-товарной фермы с. Колтуновка Алексеевского района. Памятник разрушен силосной траншеей, из которой школьниками извлечено 2 сосуда срубной культуры (Килейников, 1980, с. 9). В 1984 , 1985, 1986 гг. А.Н. Бессудновым выявлены 9 курганных памятников в Красногвардейском районе и 2 - в Валуйском (Археологические памятники..., 1992, с. 14, 21, 31, 34). В 1989-1990-х гг. разведочные работы проводились воронежским археологом А.П. Медведевым. Им открыты 3 могильника в Алексеевском районе и 1 - в Красненском (Археологические памятники..., 1992, с. 1, 2, $50)$.

В 1986-1988 гг. Новостроечной экспедицией Белгородского пединститута в рамках проведения охранных работ выявлен 51 курган, образующий 4 компактные группы в районе п. Уразово Валуйского района, из них археологическими раскопками изучено 6 курганов, относящихся к среднедонской катакомбной культуре (Петренко, 1990, с. 63). В 1990 г. Славяно-Русской экспедицией исследована одна насыпь Хотмыжского курганного могильника. По результатам ее изучения получены новые данные о вариациях 
погребального обряда северян IX-X вв. (Дьяченко, 2016, с. 57).

В 1999-2000-х гг. в районе с. Горки повторно обследован выявленный еще в 1971 г. экспедицией П.Д. Либерова курганный могильник, насчитывавший 25 насыпей. В 2003-2005 гг. Донской археологической экспедицией раскопано 12 насыпей, 5 из которых относились к эпохе бронзы, 7 - к скифскому времени (Гуляев, 2010, с. 163).

Новый этап в изучении курганных древностей региона в 2000-х гг. связан с принятием постановлений губернатора Белгородской области от 13.12.2005 № 194 «Об охране курганных памятников Белгородской области» и от 27.09.2007 № 120 «О сохранности скифских захоронений Белгородской области». В рамках первого управлению культуры области было поручено за период 2006-2010 гг. провести выявление и обследование курганов, расположенных на территории Белгородской области (Постановление..., 2005), а второго - проводить охранные археологические раскопки наиболее разрушающихся скифских захоронений (Постановление..., 2007).

Таким образом, благодаря принятию указанных нормативных актов проведено сплошное археологическое обследование всей территории области (водоразделов) на предмет наличия курганных памятников. В результате данного обследования экспедициями под руководством в 2006 г. T.В. Сарапулкиной (Борисовский район), в 2006-2009 гг. В.А. Сарапулкина (Белгородский, Яковлевский, Корочанский, Шебекинский, Вейделевский районы), в 2010-2013 гг. А.А. Божко (Ровеньский, Грайворонский, Краснояружский, Старооскольский, Чернянский, Новооскольский, Волоконовский, Губкинский, Прохоровский, Ивнянский, Валуйский, Красногвардейский, Алексеевский, Красненский районы) выявлено 923 курганных памятника (Сайт управления...).

В рамках вышеназванного постановления № 120 в 2008 г. проведены археологи- ческие раскопки 4 курганных памятников: А.П Медведевым двух курганов в районе с. Владимировка Старооскольского района, содержащих захоронения среднедонской катакомбной культуры эпохи средней бронзы (Медведев, 2008), А.В Сурковым кургана-2 у с. Таврово в Белгородском районе, относящегося к лесостепной срубной культуре (Ковалевский, 2011), Г.Л. Земцовым - кургана 1 у с. Ближняя Игуменка (Белгородский район), датированного среднедонской катакомбной культурой и срубной культурой эпохи бронзы (Ивашов, 2011). Кроме того, в 2007 г. К.Ю Ефимов исследовал курган 14 курганного могильника у с. Новоуколово катакомбной культуры (Ефимов, 2007).

Следует отметить, что после 2013 г. масштабных и целенаправленных работ по выявлению и изучению курганов в области не проводилось. Выявление отдельных курганных памятников в этот период связано с проведением обследования территорий под хозяйственное освоение. Также в рамках указанных работ в 2013 г. проведены археологические раскопки курганов 3 и 5 курганного могильника у с. Грушевка в Волоконовском районе (Божко, Остапенко, Сидоренко, 2015 , с. 145) и 1 в 2016 г. кургана 10 могильника у с. Гороженное в Корочанском районе (Кудряшов, Мельников, 2018, с. 141). Исследованные материалы соотнесены с эпохой бронзы.

Таким образом, более чем за век изучения курганных древностей на территории Белгородской области выявлено свыше 1150 курганных памятников. Вместе с тем археологическому изучению в виде раскопок подверглось всего 18 памятников (в том числе 58 насыпей), что составляет менее 2-х процентов от общего числа выявленных объектов. Учитывая данное соотношение, для понимания культурно-хронологической принадлежности курганных древностей региона актуальность для исследователей в будущем будет представлять проведение их археологических раскопок.

\section{ЛИТЕРАТУРА}

Археологические исследования в РСФСР 1934-1936 гг. Краткие отчеты и сведения / Под ред. В. В. Гольмстен; Ин-т истории материальной культуры им. Н. Я. Марра. М.; Ленинград: Изд-во Акад. наук СССР, 1941 (Ленинград). 328 с.

Археологические памятники Белгородской области / Отв. ред. А.Г. Дьяченко Вып. 1. Белгород: Управление культуры администрации Белгородской области, 1992. С. I-VIII, 1-53, IX-XV.

Археологические памятники Белгородской области / Отв. ред. А.Г. Дьяченко А.Г. Вып. 2. Белгород: Управление культуры администрации Белгородской области, 1993. С. I-VI, 1-25, VII-XIII. 
Археологические памятники Белгородской области / Отв. ред. А.Г. Дьяченко А.Г. Вып. 3. Белгород: Управление культуры администрации Белгородской области, 1995. 32 с.

Божко A.A., Остапенко А.А, Сидоренко T.E. Охранные работы в Белгородской области в 2011-2013 гг. // Археологические открытия 2010-2013 годов. / Отв. ред. Н. В. Лопатин М.: Институт археологии РАН, 2015. С. 143-145.

Гуляев В.И. На восточных рубежах Скифии (древности донских скифов). М.: ИА РАН, 2010. 344 с.

Дьяченко А.Г. Памятники раннего железного века и эпохи средневековья в лесостепном междуречье Ворсклы и Дона // Русский сборник. Вып. 8. Т. 1. / Отв. ред. Е.А. Шинаков. Брянск: РИО БГУ, 2016. C. 54-73.

Ефимов К.Ю. Охранные раскопки памятника археологии «Курганный могильник 1 у с. Новоуколово» в Красненском районе. 2007 / Архив управления государственной охраны объектов культурного наследия Белгородской области

Захарова Е.Ю. К вопросу об археологических занятиях Сергея Федоровича Платонова (раскопки 1909 г. в Валуйках) // Научные ведомости Белгородского государственного университета. Серия История. Политология. Экономика. 2014. № 1 (172). Вып. 29. С. 136-140.

Захарова Е.Ю. П.Д. Либеров и развитие археологии Среднего Дона // Вестник ВГУ. Серия: история, политология, социология. 2008. № 2. С. 62-70.

Златоверховников Н.И. Памятники старины и нового времени и другие достопримечательности Курской губернии. Курск: Кур. губ. стат. ком., 1902. 98 с.

Ивашов М.В., Земиов, Г.Л., Свиридов А.А. Охранные археологические исследования кургана у с. Ближняя Игуменка в Белгородской области // Археологические памятники Восточной Европы. Вып. 14. /Отв. ред. И.В. Федюнин Воронеж: Воронежский госпедуниверситет, 2011. С. 127-134.

Карагодин М.И. Новые находки бронзового века в Шелаево // СА. 1977. № 2. С. 229-232.

Кашкин А.В. 10 лет работы Центрально-Черноземного отряда// КСИА. №. 210. / Отв. ред. И.Т. Кругликова. М.: Наука, 1993. С. 69-76.

Килейников В.В. Отчет к Открытому листу № 313 о проведении археологических разведок по рекам Тихая Сосна и Оскол в Воронежской и Белгородской областях в 1980 году / Архив ИА РАН, Р-1, № 8138 .

Кобылин А.Н. Зеленый курган // Труды Курской ГУАК. Вып. 1. Курск, 1911. С. 25-27.

Ковалевский В.Н., Сурков А.В. Охранные раскопки кургана 2 у с. Таврово в Белгородской области // Археологические памятники Восточной Европы. Вып. 14. /Отв. ред. И.В. Федюнин Воронеж: Воронежский госпедуниверситет, 2011. С. 145-148.

Кудрямов А.Г., Мельников Е.Н. Раскопки кургана эпохи поздней бронзы у с. Гороженное Корочанского района Белгородской области // Археология восточноевропейской лесостепи. Сборник материалов международной научно-практической конференции, посвященной 80-летию со дня рождения А.Г. Николаенко (Белгород, 14-16 декабря 2017 года). / Отв. ред. В.А.Сарапулкин. Белгород: НИУ «БелгГУ», 2018. С. 141-150.

Макаренко Н.Е. Отчет об археологических исследованиях в Харьковской и Воронежской губ. в 1905 г. // Известия ИАК. Вып. 19. СПб., 1906. С. 117-156.

Материалы для истории Воронежской и соседних губерний. Воронежские акты. Т. 1. Воронеж: Воронеж. губ. стат. ком., 1887. 420 с.

Медведев А.П. Отчет о раскопках курганной группы Владимировка -1 в Старооскольском районе Белгородской области в 2008 г. Воронеж: 2009 / Архив Управления государственной охраны объектов культурного наследия Белгородской области.

Митрофанов В.В. Археологические раскопки в Валуйках в 1909 году // Клио. 2015. № 6 (102). C. $113-121$.

Отношение члена Московского Археологического Общества Магистранта Дмитрия Самоквасова на имя преосвященного Сергия Епископа Курского // Курские епархиальные ведомости. 1872. № 17. C. $1125-1128$.

Петренко Е.Н. Исследования курганов энеолита-бронзы в бассейне р. Оскол // Археологические исследования в Центральном Черноземье в 12 пятилетке. Белгород. 1990. С. 63-65.

Попова Т.В. Племена катакомбной культуры. М.: Госкультпросветиздат, 1955. 180 с.

Постановление Губернатора Белгородской области от 13.12.2005 г. № 194 «Об охране курганных памятников Белгородской области» // СПС Гарант. URL: https://base.garant.ru/26308668 (Дата обращения 20.05.2020). 
Постановление губернатора Белгородской области от 27.09.2007 г. № 120 «О сохранности скифских захоронений Белгородской области» // СПС Гарант. URL: https://base.garant.ru/26313862 (Дата обращения 20.05.2020).

Пряхин А.Д. Отчет археологической экспедиции Воронежского госуниверситета по обследованию памятников эпохи бронзы в 1968 г. / Архив ИА РАН. p-1. № 3674.

Пузикова А.И. Погребальный инвентарь курганных могильников скифского времени Среднего Подонья. М.: ИА РАН, 2017. 160 с.

Сайт управления государственной охраны объектов культурного наследия Белгородской области URL: http://okn31.ru/deyatelnost/gosudarstvennyj-uchet/ (Дата обращения 20.05.2020).

Сведения об археологических исследованиях, памятниках древности, кладах и находках // ИАК. Прибавление к вып. 34. СПб., 1910. С. 75-145.

Сосновский К.П. Городища и курганы в бассейне верхнего течения реки Псла в пределах Обоянского уезда Курской губернии // Труды Курской ГУАК. Вып. 1. Курск, 1911. С. 308-320.

Софронов А. Памятники древности, вблизи села Староселья Грайворонского уезда // Курские епархиальные ведомости. 1873. № 3. С. 120-128.

Спищылн A.A. Обозрение некоторых губерний и областей России в археологическом отношении. III. Воронежская губерния // Записки Императорского Русского Археологического Общества. T. VIII, Вып. 1-2. СПб.: Типография И.Н. Скороходова, 1896. С. 132-140.

Cпищьлн A.A. Обозрение Курской губ. в археологическом отношении //Курский сборник. Вып. I. Курск: Типография Губернскаго Правления, 1901. С. 97-100.

Спищын А.А. Сведения 1873 г. о городищах и курганах. Предисловие // Известия ИАК. Вып. 5. Спб., 1903. C. 1-4.

\section{Информация об авторах:}

Святой Ян Сергеевич, сотрудник, Белгородская региональная общественная организация «Общество любителей древней истории» (г. Белгород, Россия); yan.sviatoi@yandex.ru

Костылёва Анастасия Андреевна, консультант отдела государственного учёта и регулирования градостроительной деятельности управления государственной охраны объектов культурного наследия Белгородской области (г. Белгород, Россия); kostileva89@mail.ru

\section{REFERENCES}

In Golmsten, V. V. (ed.). 1941. Arkheologicheskie issledovaniia v RSFSR. 1934-1936 gg. Kratkie otchety i svedeniia (Archaeological Investigations in the Russian Federation in 1934-1936: Brief Reports and Data). Moscow; Leningrad: Academy of Sciences of the USSR Publ. (in Russian)

D’yachenko, A. G. (ed.). 1992. Arkheologicheskie pamiatniki Belgorodskoi oblasti (Archaeological Monuments of the Belgorod Oblast) 1. Belgorod: Department of Culture of the Administration of the Belgorod Oblast (in Russian).

D’yachenko, A. G. (ed.). 1993. Arkheologicheskie pamiatniki Belgorodskoi oblasti (Archaeological Monuments of the Belgorod Oblast) 1. Belgorod: Department of Culture of the Administration of the Belgorod Oblast (in Russian).

D’yachenko, A. G. (ed.). 1995. Arkheologicheskie pamiatniki Belgorodskoi oblasti (Archaeological Monuments of the Belgorod Oblast) 1. Belgorod: Department of Culture of the Administration of the Belgorod Oblast (in Russian).

Bozhko, A. A., Ostapenko, A. A., Sidorenko, T. E. 2015. In Lopatin, N. V. (ed.). Arkheologicheskie otkrytiia 2010-2013 gg. (Archaeological Discoveries of 2010-2013). Moscow: Institute of Archaeology, Russian Academy of Sciences, 143-145 (in Russian).

Gulyaev, V. I. 2010. Na vostochnikh rubezhakh Skifii (drevnosti donskikh skifov) (On the Eastern Borders of Scythia (Antiquities of the Don Scythians). Moscow: Intitute of archaeology RAS (in Russian).

D’yachenko, A. G. 2016. In Shinakov, E. A. (eds.). Russkii sbornik (Русский сборник) 8(1). Bryansk: Bryansk State University, 54-73 (in Russian).

Efimov, K. Yu. 2007. Okhrannye raskopki pamiatnika arheologii "Kurgannyi mogil'nik 1 us. Novoukolovo" $v$ Krasnenskov raione. 2007 (Resque excavation of archaeological site "the Kurgan burial ground 1 near Novoukolovo Village" in Krasnensky District 2007). Archive of the Department of State Protection of Cultural Heritage Sites of the Belgorod Oblast (in Russian). 
Zakharova, E. Yu. 2014. In Nauchnye vedomosti Belgorodskogo gosudarstvennogo universiteta. Istoriya. Politologiya (Belgorod State University Scientific Bulletin History Political Science) 1 (172). Issue 29. 136-140 (in Russian).

Zakharova, E. Yu. 2008. In Vestnik Voronezhskogo Gosudarstvennogo universiteta. Seriia «Istoriia, politologiia, sociologiia» (Bulletin of the Voronezh State University. History, Political Science, Sociology Series) (2). 62-70 (in Russian).

Zlatoverkhovnikov, N. I. 1902. Pamiatniki stariny i novogo vremeni $i$ drugie dostoprimechatel'nosti Kurskoj gubernii (Monuments of Antiquity and the Modern Age and other Sights of Kursk Governorate). Kursk (in Russian).

Ivashov, M. V., Zemtsov, G. L., Sviridov, A. A. 2011. In Fediunin, I. V. (ed.). Arkheologicheskie pamiatniki Vostochnoi Evropy (Archaeological Sites of Eastern Europe) 14. Voronezh: Voronezh State Pedagogical University, 127-134 (in Russian).

Karagodin, M. I. 1977. In Sovetskaya arkheologiya (Soviet Archaeology) 2. 229-232 (in Russian).

Kashkin, A. V. 1993. In Kruglikova, I. T. (ed.). Kratkie soobshcheniia Instituta arkheologii (Brief Communications of the Institute of Archaeology) 210. Moscow: "Nauka" Publ., 69-76 (in Russian).

Kileinikov, V. V. 1980. Otchet $k$ Otkrytomu listu № 313 o provedenii arheologicheskikh razvedok po rekam Tihaya Sosna i Oskol v Voronezhskoj i Belgorodskoj oblastjah v 1980 godu (Report to Permit for Archaeological Excavations and Surveys No. 313 on the Archaeological Exploration along the Tikhaya Sosna and Oskol Rivers in the Voronezh and Belgorod Oblasts in 1980). Archive of the Institute of Archaeology of the Russian Academy of Sciences, R-1, no 8138 (in Russian).

Kobylin, A. N. 1911. In . In Trudy Kurskoi gubernskoi uchenoi arkhivnoi komissii (Proceedings of the Kursk Provincial Academic Archival Commission) I. Kursk, 25-27. (in Russian).

Kovalevsky, V. N., Surkov, A. V. 2011. In Fediunin, I. V. (ed.). Arkheologicheskie pamiatniki Vostochnoi Evropy (Archaeological Sites of Eastern Europe) 14. Voronezh: Voronezh State Pedagogical University, 145-148 (in Russian).

Kudryashov, A. G., Mel'nikov, E. N. 2018. In Sarapulkin, V. A. (ed.). Arkheologiia Vostochnoevropeiskoi lesostepi (Archaeology of the East-European Forest-Steppe Zone). Belgorod: Belgorod National Research University, 141-150 (in Russian).

Makarenko, N. E. 1906. In Izvestiia Imperatorskoi arkheologicheskoi komissii (Proceedings of the Imperial Archaeological Commission) 19. Saint Petersburg, 117-156 (in Russian).

1887. Materialy dlja istorii Voronezhskoi i sosednih gubernij. Voronezhskie akty. (Materials on the History of the Voronezh and Neighboring Governorates. Voronezh Acts) 1. Voronezh (in Russian).

Medvedev, A. P., 2009. Otchet o raskopkakh kurgannoi gruppy Vladimirovka-1 v Starooskol'skom rajone Belgorodskoi jblasti v 2008 g. (Report on the Excavations of Vladimirovka-1 Burial Mound Group in the Starooskolsky District of Belgorod Oblast in 2008) Archive of the Department of State Protection of Cultural Heritage Sites of the Belgorod Oblast (in Russian).

Mitrofanov, V. V. 2015. In Klio. 102 (6). 113-121 (in Russian).

Samokvasov, D. 1872. In Kurskie eparhial'nye vedomosti (Kursk Diocesan Gazette) 17, 1125-1128 (in Russian).

Petrenko, E. N. 1990. In Arkeologicheskie issledovaniia v Centralnom Chernozem'e v 12 piatiletke (Archaeological Studies in the Central Black Earth Region in the 12th Five-Year Period) Belgorod, 63-65 (in Russian).

Popova, T. V. 1955. Plemena katakobnoi kul'tury (Tribes of the Catacombnaia Culture). Moscow (in Russian).

Postanovlenie Gubernatora Belgorodskoi oblasti ot 13.12.2005 g. № 194 "Ob ohrane kurgannyh pamjatnikov Belgorodskoi oblasti" (Resolution of the Governor of the Belgorod Oblast No. 194 dated December 13, 2005 "On the Protection of Burial Mounds in the Belgorod Oblast"). Available at: https://base. garant.ru/26308668 (Accessed 20.05.2020).

Postanovlenie gubernatora Belgorodskoi oblasti ot 27.09.2007 2. № 120 "O sokhrannosti skifskikh zakhoronenii Belgorodskoi oblasticкой области" (Resolution of the Governor of the Belgorod Oblast No. 120 dated September 27, 2007 "On the Preservation of Scythian Burials in the Belgorod Oblast"). Available at: https://base.garant.ru/26313862 (Accessed 20.05.2020).

Pryakhin,A. D. 1968. Otchet arkheologicheskoi ekspeditsii Voronezhskogogosuniversiteta po obsledovaniyu pamyatnikov epokhi bronzy v 1968 g. (Report by the Archaeological Expedition of Voronezh State University 
on the Survey of Bronze Age Monuments in 1968). Moscow. Archive of the Institute of Archaeology of the Russian Academy of Sciences, R-1, no. 3674 (in Russian).

Puzikova, A. I. 2017. Pogrebal'nyi inventar' kurgannyh mogil'nikov skifskogo vremeni Srednego Podon'ia (Funeral goods from kurgan cemeteries of the scythian time in the Middle Don region). Moscow.: Institute of archaeology, Russian Academy of Sciences.

Sait upravleniia gosudarstvennoi okhrany obektov kul'turnogo naslediia Belgorodskoi oblasti (Site of the Department of State Protection of Cultural Heritage Sites of the Belgorod Oblast) Available at: http://okn31. $\mathrm{ru} /$ deyatelnost/gosudarstvennyj-uchet/ Accessed 20.05.2020).

Svedeniia ob arkheologicheskikh issledovaniiakh, pamiatnikakh drevnosti, kladakh I nakhodkakh (Information on Archaeological Studies, Monuments of Antiquity, Hoards and Findings) 1910. Izvestiia Imperatorskoi arkheologicheskoi komissii (Proceedings of the Imperial Archaeological Commission), appendix to issue 34. Saint Petersburg, 75-145 (in Russian).

Sosnovskiy, K. P. 1911. In Trudy Kurskoi gubernskoi uchenoi arkhivnoi komissii (Proceedings of the Kursk Provincial Academic Archival Commission) X. Kursk, 308-320. (in Russian).

Sofronov, A. 1873. In Kurskie eparhial'nye vedomosti (Kursk Diocesan Gazette) 3, 120-128 (in Russian).

Spitsyn, A. A. 1896. In Zapiski Imperatorskogo Russkogo arkheologicheskogo obshchestva (Proceedings of the Imperial Russian Archaeological Society) VIII, 1-2, Saint Petersburg: Skorokhodov's I. N. typography, 132-140 (in Russian).

Spitsyn, A. A. 1901. In Kurskii sbornik (Kursk Collection) 1, 97-100 (in Russian).

Spitsyn, A. A. 1903. In Izvestiia Imperatorskoi arkheologicheskoi komissii (Proceedings of the Imperial Archaeological Commission) 5. Saint Petersburg, 1-4 (in Russian).

\author{
About the Authors: \\ Svyatoy Yan S., Belgorod regional public organization "Ancient History Society". Nagornaya Str., 25, \\ office 47, Belgorod, 308001, Russian Federation; yan.sviatoi@yandex.ru \\ Kostileva Anastasiya A., Department of State Protection of Cultural Heritage Sites of the Belgorod Oblast. \\ Grazhdansky Prospekt.., 41, Belgorod, 308000, Russian Federation; kostileva89@mail.ru

